\title{
REPRESENTACIONES DEL PROFESOR EN FORMACIÓN DE HISTORIA, GEOGRAFÍA Y CIENCIAS SOCIALES SOBRE EL PUEBLO MAPUCHE
}

\author{
Dr. Gerardo SÁNCHEZ S ${ }^{1}$. \\ Mg. Ximena JARA A. ${ }^{2}$ \\ Prof. Jennifer Correa C. ${ }^{3}$ \\ Prof. Pía Crespo C. ${ }^{4}$ \\ Prof. Nicolás Sánchez C. 5
}

\section{Resumen}

La investigación tiene como objetivo determinar las representaciones que tienen los profesores en formación de Historia, Geografía y Ciencias Sociales respecto del pueblo mapuche. Con un enfoque cualitativo y a través del uso de focus group a 40 estudiantes, se concluye que la problemática mapuche no ha logrado ser relevada dentro de su formación inicial, aun cuando consideran que es una temática necesaria de trabajar en el contexto de la educación secundaria.

Palabras claves: Profesor en formación - pueblo mapuche - historia - representaciones

\begin{abstract}
The research aims to identify the representations that have student teachers of History, Geography and Social Sciences about the Mapuche people. With a qualitative approach and through the use of focus group 40 students, we conclude that the Mapuche issue has failed to be relieved within their initial training, even when they believe it is a necessary theme of work in the context of secondary education.
\end{abstract}

Keywords:Teacher training - Mapuche people - history - representations

\footnotetext{
${ }^{1}$ Universidad Católica del Maule

Avda. San Miguel 3605, Talca gsanchez@ucm.cl

${ }^{2}$ Universidad Autónoma de Chile

5 Poniente 1670, Talca xijara22@uautonoma.cl

3 jcorrea.caceres@gmail.com

423.belen.crepo@gmail.com

${ }^{5}$ nico.sanchez.cubillos@gmail.com

Fecha de recepción del artículo: Agosto 2015

Fecha de evaluación: Noviembre 2015
} 


\section{Résumé}

La recherche vise à identifier les représentations qui ont les professeurs d'histoire, de géographie et de sciences sociales élèves à propos du peuple mapuche. Avec une approche qualitative et grâce à l'utilisation de groupes de discussion 40 étudiants, nous concluons que la question Mapuche a manqué d'être relevée au sein de leur formation initiale, même quand ils croient qu'il est un thème de travail nécessaire dans le contexte de l'enseignement secondaire.

Mots clé :La formation des enseignants - Mapuches - histoire - représentations

\section{PLANTEAMIENTO DEL PROBLEMA}

En nuestro país, según la Constitución Política de la República son chilenos todas las personas

Nacidos en el territorio de Chile, con excepción de los hijos de extranjeros que se encuentren en Chile al servicio de su Gobierno, y de los hijos de extranjeros transeúntes, todos los que sin embargo, podrán optar por la nacionalidad chilena (Artículo 10. Capítulo II Nacionalidad y Ciudadanía. Constitución Política de la República)

Sin embargo, pese a que legal y jurídicamente se identifica y homogeneiza a las personas por el territorio y límites nacionales específicos en los cuales nacieron y viven, actualmente existen diversos grupos de personas en nuestro país que no se sienten chilenos.

Uno de estos grupos son las personas pertenecientes al pueblo originario mapuche, (entendido como pueblo prehispánico que habitaba el continente Americano antes del "descubrimiento"6 y conquista por parte de los europeos), que en las últimas décadas han protagonizado el revivir del "conflicto mapuche" repercutiendo en las diversas áreas de la sociedad.

El gobierno ha tratado de incorporar la cultura indígena al sistema educativo chileno a través de diversas políticas y programas como lo es la Educación Intercultural Bilingüe (EIB) en tanto propuesta educativa, que pretende visibilizar la educación indígena mediante la enseñanza de una lengua materna como segundo lenguaje después del castellano, solamente en zonas de alta densidad de comunidades o habitantes indígenas, lo que provoca que, el resto de los estudiantes no tengan acceso a la cultura y a la Educación Intercultural Bilingüe, como es el caso de la región del Maule que, según el censo del año 2012, posee un 4,24\% de población indígena.

Con respecto a esto es importante mencionar que,

La educación es el proceso de aprendizaje permanente que abarca las distintas etapas de la vida ético, moral, afectivo, intelectual, artístico y físico... Se enmarca en el respeto y valorización de los derechos humanos y en las libertades fundamentales, de la diversidad multicultural y de la paz, y de nuestra

\footnotetext{
${ }^{6}$ Entendiendo "descubrimiento" desde el punto de vista europeo occidental de los colonizadores españoles al encontrarse con el Continente Americano y sus habitantes cara a cara, llamándole a este territorio "Nuevo Mundo o las Indias"
} 
identidad nacional capacitando a las personas para conducir su vida en forma plena, para convivir y participar en forma responsable, tolerante, solidaria, democrática y activa en la comunidad, y para trabajar y contribuir al desarrollo del país (Ley General de educación: 2-3)

Precisamente en la interpretación de esta ley y el cumplimiento total de los objetivos de programas como el Educación Intercultural Bilingüe se encuentra la base del conflicto mapuche en el área de educación, puesto que este pueblo originario base del mestizaje y creación del pueblo chileno no se siente integrado, ni mucho menos incluido o parte de la sociedad chilena actual al no reconocer ésta la diversidad multicultural existente en ella, que forma parte ineludible de la identidad nacional tal como lo argumenta la organización identidad territorial Lafkenche (Temuco, octubre 2013), que cree en la necesidad de formular una Nueva Constitución para Chile ${ }^{7}$.

En un marco geográfico más amplio, los países pertenecientes a la región Latinoamérica, reconocen y concuerdan que tienen una deuda histórica con los diversos pueblos originarios en cuanto a la participación indígena dentro del Estado y de la sociedad, puesto que ésta, se ha visto coartada o incluso ignorada desde la llegada de los europeos al continente americano en el siglo XV, producto del predominio de una sola cultura sobre otra (en este caso la europea), reflejada en las formas de organización política, económica, social, las costumbres y creencias de los nativos, considerados como "bárbaros", lo que provocó la invisibilización de los pueblos originarios que con la creación de la idea de Estado Nación persiste hasta el día de hoy.

Conflicto no menor, teniendo en cuenta que, en la República de Chile en el año 2014 de una población total de 17,8 millones de habitantes según fuentes otorgadas por el Instituto Nacional de Estadística, 1.714.677 son pertenecientes y descendientes de algún pueblo indígena de nuestro país sean estos Aymará, Quechua, Collas, Diaguitas, entre otros; y de esta cifra un $84,11 \%$ pertenece al Pueblo Mapuche, siendo esta la etnia más numerosa con un total de 1.442 .214 personas, emplazándose principalmente en la Novena Región, con un 33,6\%, Región Metropolitana 30,3\%, y Décima Región con un $16,7 \%$ (INE y Programa Orígenes, 2005).

Al invisibilizar la sociedad chilena una de sus raíces, en este caso específico el pueblo mapuche, y enaltecer la raíz europea para la creación y desarrollo de la cultura nacional se han ido observando e identificando diversas situaciones y elementos discriminatorios presentes en la sociedad y educación

Desde la perspectiva de Fernández (2005), se sigue pensando en los indígenas como "minorías", como sujetos carentes, sumisos, sin mayor capacidad propositiva.

Por lo cual, el sentimiento de desigualdad social, política, cultural y educativa por parte de los pueblos originarios se hace cada vez más un sentir generalizado que abre una herida cuya data se sitúa a fines del siglo XV y principios del XVI, lo cual no reflejaría por parte de estos pueblos la igualdad como chilenos ante la ley; contrariamente a lo que la Constitución asegura a todas las personas:

\footnotetext{
${ }^{7}$ En donde se debe "reconocer la preexistencia de los Pueblos Originarios y establecerse sobre la base política y jurídica de un Estado Plurinacional e Intercultural, como una nueva forma de relacionarnos en la diversidad"
} 
En Chile no hay persona ni grupo privilegiados. En Chile no hay esclavos y el que pise su territorio queda libre. Hombres y mujeres son iguales ante la ley. Ni la ley ni autoridad alguna podrán establecer diferencias arbitrarias (Constitución Política de Chile, Inciso 2. Artículo n ${ }^{\circ} 19$. Capítulo III De los Derechos y Deberes Constitucionales)

Desde la perspectiva historiográfica y reforzada por el sistema escolar, encontramos narraciones de época que refieren a este grupo de personas como indígenas, no siendo considerados primitivos pero si en un Estado de barbarie por las características guerreras y de resistencia de su gente, por lo tanto violentos a los ojos del conquistador europeo, como lo ejemplifica Francisco Encina en la siguiente cita:

"Por su parte Pedro de Valdivia, refiriendo su primer reconocimiento a la región del Biobío, dice: "A 11 de febrero de dicho año (1546) partí e camine treinta leguas, que era a tierra que nos servía y que habíamos corrido; pasadas diez leguas adelante, topamos mucha población, e a las dieciséis, gente de guerra que nos salían a defender los caminos y pelear... y un día por la mañana salieron hasta trescientos indios a pelear con nosotros" (Encina, 1949: 82)

Según lo señalado por el autor, los españoles llegados a Chile se dan cuenta tardíamente del coraje, energía guerrera e impulso combativo del mapuche reflejado en su imaginación y táctica militar organizada no reconocida en ese entonces por los conquistadores, situación que el generar desconcierto, los llevó al punto de llegar a dudar si eran realmente seres humanos.

En ese sentido, personajes como el Capitán Fitz Roy y el naturalista inglés Charles Darwin, comentan lo siguiente:

"Cuando vemos a estos hombres, dice el último, apenas se puede creer que sean criaturas humanas, habitantes del mismo mundo que nosotros". Y más adelante agrega: "Yo creo que el hombre en esta parte extrema de América es más degradado que en cualquier otro lugar de la tierra. Comparadas a los fueguinos, las dos razas de insulares del grande océano, los esquimales y los australianos, son civilizados". (Barros Arana, 2000:41)

Tal como dice José Bengoa en su libro Historia del Pueblo Mapuche, la mayoría de los autores que han escrito respecto al tema, se han referido a los mapuches como bárbaros, estando influenciados por el concepto decimonónico de barbarie, el cual alude a que un pueblo, persona o tribu que no es civilizado, al no tener organización, leyes y autoridades a las cuales se sometan, por lo tanto, viven en un constante estado de guerra. Sin embargo,

"No siempre ha existido esta idea de que los antiguos eran más barbaros que los modernos. Por el contrario, en las tradiciones orientales, griegas, y hasta la edad media, se veía a la sociedades primitivas como viviendo en el paraíso, siendo puras y morales" (Bengoa, 2012:26)

La constitución de la nacionalidad chilena al requerir de antecedentes y de un pasado ideológico está marcada por el problema indígena visto desde una perspectiva heroica, de guerra a muerte o sangre derramada en defensa de la libertad, dependiendo las circunstancias o fines estatales. 
Por ejemplo, la primera experiencia a la que se alude tiene directa relación con el descubrimiento y primer encuentro de los españoles con el araucano, en el cual desde la mirada chilena criolla de que el araucano estaba en el bando contrario, estos se comportaban salvajemente, surgiendo el estereotipo de que este pueblo originario era bárbaro, salvaje, con costumbre degradantes, borrachos, flojos, pero valientes y crueles para la guerra, características y razones por las cuales,

"Llegará el momento en que el país santiaguino, civilizado, culto, gritara unánimemente: ¡acabad con ellos! Y el estereotipo se mantendrá hasta hoy: flojos, borrachos, lentos y lerdo. No nos podremos explicar por qué gente de estas características mantuvieron a raya a los tercios de España y al glorioso ejército chileno, durante tantos años." (2012:149)

Pasando a ser sin embargo, después de la consolidación de la Republica héroes de antaño y, por otra parte el simbolismo de sangre derramada es utilizada en el color rojo de la bandera chilena, como una forma de representatividad nacional, que si bien conocemos su significado, poco recordamos de la lucha sangrienta que tuvo como resultado el proceso de colonización y ocupación de la Araucanía a fines del siglo XIX en donde, el araucano tuvo que huir con familia y animales y otras veces fue muerto por nuestros mismos compatriotas en batalla debido a que durante el proceso la independencia indígena los criollos chilenos veían en los araucanos una sociedad bárbara con la cual,

"No había alianza posible, no había ninguna forma de integración que no pasara por el sometimiento, por la llamada civilización, la perdida de la libertad y la independencia y, en buena medida, por el exterminio." (2012:250)

Según Bengoa, estos hechos no le quitan el mérito a la resistencia mapuche que, pese a la enorme desventaja material con la que se enfrentaban, numerosos testimonios de mapuches dan cuenta de la defensa de sus tierras, incluso cuando sabían que la lucha era desigual y que por ende se podía morir en la defensa o en términos políticos al menos llegar a un acuerdo con el conquistador.

Enmarcado en las características del alma guerrera, el heroísmo del indígena y su constante persistencia del pueblo, por proteger y recuperar lo que es parte de ellos, se produce uno de los principales actos de resistencia llevado a cabo por el pueblo mapuche y recordado, como uno de los actos de mayor valentía es, El alzamiento general del año 1881(2012:285)

En dicha insurrección, participaron la mayor parte de grupos mapuches, y muchos otros que nunca antes habían participado en una guerra, aun a pesar de que muchos caciques se opusieran, declarándose como naturales, ante el conflicto, la organización de la insurrección continuó su camino. De acuerdo a lo acordado, cada agrupación, debía atacar el lugar donde vivieran los huincas, ya fuese un fuerte, un pueblo o una reciente mansión instalada, teniendo como objetivo principal el lograr,

“(...) expulsar al huinca del territorio (mapu); aunque fuera un objetivo imposiblemirado desde la perspectiva de hoy-expresa el elemento cultural central que unía al pueblo: su independencia y libertad." (2012:285) 
Con este importante hito cultural, se cierra una etapa cargada de heroísmo para la historia del pueblo mapuche, dando pie, a un nuevo periodo, que se caracterizó por un periodo de lucha por la tierra y la defensa de su identidad.

"A partir de la derrota militar de 1881 y la ocupación de Villarrica en 1883, cambió la sociedad mapuche internamente, como también su relación con el Estado y la sociedad chilena.” (2012: 327)

La ocupación y reducción territorial, fue una de las particularidades centrales y más evidentes de los cambios que se suscitaron, entre ellos fueron relevantes: el decreto de la Araucanía como propiedad fiscal, la colonización de tierras que servirían para ponerlas a producir, argumentando que el indígena, no las sabían utilizar idóneamente. Por otro parte, los mapuches se vieron sometidos como señala Bengoa, al rigor de la civilización, ya que debieron acatar las leyes impuestas para ellos por el estado chileno, encabezadas en las manos de ejército nacional; se les entregaron pequeñas mercedes de tierras, encerrándolos en reducciones y obligándolos a trabajar las tierras, transformándose en agricultores, campesinos, productores de sus propia subsistencia, y sus principales hombres guerreros se convirtieron en ciudadanos, que acata las leyes del estado chileno,

"Fueron años de temor, de pestes, de hambre, de pérdida de una identidad y reformulación de una nueva cultura como minoría étnica enclavada en la sociedad rural chilena." (2012:327)

Los primeros años de cambio eran de completo desconcierto en especial, para el pueblo indígena y viejos caciques que no lograban entender su derrota. Por otro lado los chilenos discutían el camino a seguir con estos casi cien mil mapuches, el ejército respetaba y utilizaba la estructura del cacicazgo; forzó en cada localidad el poder de los caciques y utilizó ellos para lograr controlar a la población. Sin embargo,

“(...) colonos, comerciantes e industriales interesados en la ocupación rápida de los territorios, realizaron una campaña que sostenía que la Araucanía estaba despoblada y era necesario medir, lotear y rematar. " (2012:329)

Los administrativos del estado y funcionarios civiles, en tanto, buscaban llevar a cabo una política de rápida integración de los mapuches a la sociedad chilena, para transformarlos rápidamente en masa obrera y campesina del país, ya que veían la derrota del pueblo mapuche como el fin de la raza indígena., no obstante solo quedaba salvar a las personas, apoyando su integración rápida y expedita.

El proceso de radicación sufrido por el pueblo mapuche, transformó completamente su organización social, debieron cambiar sus costumbres, su sistema alimenticio, formas de cultivo y producción de subsistencia y ganadería a menor escala, en conclusión una suerte de campesinización forzosa de esta sociedad.

En consecuencia, la imagen que tienen muchos personas, adultas, jóvenes y niños de los pueblos indígenas que habitan el territorio chileno ha sido transmitida por la escuela formal, a través de una educación occidentalista, en donde la asignatura de Historia, Geografía y Ciencias Sociales ha tenido un rol protagónico en la transmisión de determinadas representaciones, prejuicios, mitos, e interpretaciones, sobre los pueblos originarios, el pueblo mapuche. Lo anterior como producto de decisiones curriculares 
que nunca resultan neutrales en términos de determinadas visiones y modelos que intentan comunicar.

Ejemplo de esta situación en educación, la encontramos en el currículo nacional en el subsector de Historia, Geografía y Ciencias Sociales, en específico en los contenidos de Historia de Chile, $2^{\circ}$ año de educación general básica y $2^{\circ}$ año de enseñanza secundaria, que apunta al abordaje de una enseñanza de los pueblos originarios y sus características, reflejado en los textos de estudio y libros escolares, en donde los contenidos se exponen y organizan en la siguiente lógica: pueblos indígenas antes de la llegada de los españoles, su ubicación geográfica, formas de organización económica y social, formas de vida, métodos de recolección, formas de trabajo, resistencias, guerras o enfrentamientos con los españoles y algunas de sus tradiciones más características y relevantes según los propósitos del Estado para la formación de los estudiantes.

Es preciso mencionar que en $6^{\circ}$ año básico, el tema es abordado en la descripción de la conformación de territorio de Chile durante el siglo XIX, en donde los contenidos contemplan: colonizaciones europeas, la incorporación de la Isla de Pascua, Ocupación de la Araucanía, Guerra del Pacifico y diversos conflictos bélicos, entre otros factores, dichos tópicos evidencian la continuidad en la materia y los contenidos de los pueblos originarios y sus transformaciones a lo largo de los siglos, estudiados en $2^{\circ}$ año básico y retomados nuevamente en $2^{\circ}$ año medio.

Los docentes en formación como ciudadanos y maestros de futuras generaciones son los encargados de enseñar y formar ciudadanos; tal cual lo confirma la Ley General de Educación, en términos de inculcar en nuestros estudiantes la importancia y valoración de los pueblos originarios, base fundamental de nuestra sociedad chilena y patrimonio viviente.

En consecuencia, los Profesores de Historia, Geografía y Ciencias Sociales son los responsables del rescate de la identidad nacional y regional; teniendo el deber fundamental de reconocer a los pueblos originarios, y proporcionar los elementos formativos que permitan a los estudiantes comprender la naturaleza del conflicto mapuche y su contingencia. Para ello, debe conocer en primer lugar los problemas y conflictos culturales existentes en nuestro Chile Contemporáneo $\mathrm{y}$, otorgar diversas visiones a los estudiantes de enseñanza media, para que como ciudadanos en una República democrática logren hacer efectiva su ciudadanía a través de una mayor información y participación en sus contextos de vida.

La escuela al ser el segundo espacio de socialización en la vida de un ser humano, requiere docentes capaces de cumplir con su labor de maestro, guía y orientador para que el educando valorice y ponga en práctica su sentido social, debido a que si en la familia no se dan las instancias para una interculturalidad y bases de la inclusión, el docente es el principal sujeto irradiador y responsable de la enseñanza, inculcación, y respeto por la diversidad que presentan los pueblos originarios chilenos en una nación multicultural.

Al reconocer que la realidad nacional obedece a una multiculturalidad, la sociedad postmoderna se hace consciente de la influencia regional local e inserción del país en el contexto mundial, en donde la heterogeneidad de los individuos y grupos de personas toma un nuevo valor social, cultural y político sobre la homogeneidad; presente también en el proceso de enseñanza aprendizaje, base para el desarrollo ético, moral, respeto de 
los derechos humanos, diversidad cultural, identidad nacional y, actuación en forma responsable para el desarrollo integral del país, proceso en el cual surgen diversos cuestionamientos en el plano de la educación, como por ejemplo:

¿Todos los estudiantes son iguales?, ¿Cómo reconocer y valorar sus diferencias? ¿Se les debe enseñar lo mismo?, ¿Hay que segregarlos por niveles o por habilidades?, ¿La cultura predominante en la enseñanza debe ser la europea occidental en desmedró de la cultura originaria?, ¿Se deben privilegiar los contenidos sobre el aprendizaje significativo?, ¿Deben existir programas especiales para los pueblos originarios?, ¿Estos programas son segregadores o integradores?, ¿Qué es lo que realmente se quiere y requiere como sociedad?

Entendiendo que la formación inicial tiene una responsabilidad en el tipo de sociedad que se pretende construir, enfrenta el desafío de formar un profesor que:

"Comprende los conceptos y preguntas centrales propias de las Ciencias Sociales y su aplicación al conocimiento y comprensión del funcionamiento de la sociedad", el futuro profesor o profesora entiende que las sociedades pasadas y presentes son producto de una construcción compleja y dinámica y que las disciplinas sociales aportan al conocimiento de los procesos y acontecimientos sociales, políticos, económicos y culturales construyendo interpretaciones acerca de los mismos en determinado tiempo y espacio. Lo que se evidencia cuando: comprende que la cohesión social en sociedades altamente diferenciadas y desiguales exige a las personas actitudes de responsabilidad social, principios de equidad y la presencia de instituciones inclusivas y valoradas como legítimas; caracteriza la sociedad contemporánea como una sociedad multicultural y explora algunas de ellas para comprenderlas en su contexto y en su relación con otras, evaluando si se trata de una relación integradora, discriminadora $o$ confrontacional; analizan críticamente, utilizan apropiadamente y establecen relaciones entre los conceptos fundamentales de esta área, tales como identidad, diversidad cultural y sus fuentes principales (como etnia, nacionalidad, religión), sociedad, cultura, patrimonio, estereotipos y prejuicios, multiculturalidad; y reconoce los aportes pasados y presentes provenientes de los diversos grupos étnicos, lingüísticos, religiosos e ideológicos que han configurado y configuran la comunidad en que vive (Ministerio de Educación 2011: 155)

En ese escenario se inscribe el presente estudio, que busca indagar en las representaciones e imaginario construido por los profesores en formación del área de Historia, Geografía y Ciencias Sociales del pueblo mapuche, específicamente en lo referido al nivel de conocimiento que posee de la temática y la importancia otorgada en la formación de las futuras generaciones.

\section{OBJETIVO GENERAL:}

Determinar los conocimientos y la importancia que le otorga el Profesor de Historia, Geografía y Ciencias Sociales en formación al pueblo mapuche.

\section{OBJETIVOS ESPECÍFICOS:}

1. Conocer la percepción y valoración que tienen los docentes en formación, sobre el pueblo mapuche chileno. 
2. Reconocer la importancia que los Profesores de Historia, Geografía y Ciencias Sociales le otorga a la cultura y conflicto Mapuche.

3. Determinar el conocimiento y apropiación del marco curricular respecto al tema de los pueblos originarios.

\section{DISEÑO METODOLÓGICO DE LA INVESTIGACIÓN}

Dentro de los paradigmas existentes, el escogido como base de esta investigación es el cualitativo, debido a que este posee un fundamento netamente humanista, cuya principal motivación es entender la realidad y vida social, determinando una realidad percibida como dinámica, viva y conocible para todos los participantes en la interacción social. El mundo social no es estático, ni fijo, por el contrario es cambiante y dinámico, existiendo múltiples realidades que cada individuo construye y determina como agente activo, siendo un proceso negociado e interpretativo, en una trama aceptada de interacción, donde se hace hincapié en la compresión desde la perspectiva de los participantes.

El enfoque cualitativo, consiste en un conjunto de prácticas interpretativas que transforman y convierten al mundo visible, en una sucesión de representaciones, como observaciones, anotaciones, grabaciones y documentos, lo que lo hace ser naturalista (porque estudia a los objetos y seres vivos en sus contextos o ambientes naturales y cotidianidad) e interpretativo (pues intenta encontrar sentido a los fenómenos en función de los significados que las personas les otorguen).

El alcance de esta investigación dentro del enfoque cualitativo de investigación es el Descriptivo $^{8}$, debido a que, dentro de las características de este estudio se busca especificar los perfiles importantes y/o relevantes de personas, grupos, comunidades o algún otro fenómeno u objeto de estudio que se somete a análisis. Además, de describir situaciones, eventos y hechos, por medio de la recolección de datos diversos referente a la temática a estudiar.

Esta investigación cualitativa es de carácter no experimental puesto que, se observan los fenómenos tal como se dan en el contexto natural, sin manipulación deliberada de las variables.

Desde el punto de vista de su temporalidad es transaccional o transversal, ya que la recolección de datos se realizó en un momento dado o en periodo exacto y determinado, correspondiente al primer semestre del presente año.

En consecuencia, el diseño de esta investigación tiene características del diseño etnográfico y fenomenológico, debido a que se desea describir los conocimientos del pueblo mapuche que tiene la población escogida $\mathrm{y}$, por otra parte determinar la importancia de este conocimiento en base al significado que le dan los docentes en el curriculum nacional, estudiando elementos relacionados con el lenguaje, estructuras sociales, políticas, económicas, educativas y religiosas, creencias, vida cotidiana e interacciones sociales actuales.

Álvarez - Gayou (2003) considera que el propósito de la investigación etnográfica es describir y analizar lo que las personas de un sitio, estrato o contexto determinado hacen usualmente; así como los significados que le dan a ese

\footnotetext{
${ }^{8}$ Según Danhke (1089) se dividen los tipos de estudios en exploratorios, descriptivos, correlacionales y explicativos.
} 
comportamiento realizado bajo la circunstancias comunes o especiales, y finalmente, presenta los resultados de manera que se resalten las regularidades que implica un proceso cultural (Hernández 2010: 501)

\section{Población de Estudio}

La población participante del estudio corresponde a un total de 40 estudiantes de pedagogía en Historia para el nivel de enseñanza media, los cuales fueron organizados en cinco focus group, para proceder a la recopilación de la información, correspondiendo a un tipo de muestra no probabilística por conveniencia, siendo además un muestreo aleatorio de carácter estratificado.

Se utilizó como instrumento de recolección de datos el grupo focal, donde

Existe un interés por parte del investigador por cómo los individuos forman un esquema o perspectiva de una problema, a través de la interacción (Hernández 2010: 425)

Desde el punto de vista logístico, en cada grupo focal, el moderador trabaja partiendo desde un conjunto predeterminado de tópicos de discusión, obteniendo datos e información de lo que se extrae y dicen los participantes durante esta discusión grupal.

Se dispuso de un total de 10 preguntas semiestructuradas, las cuales son útiles tanto para al moderador, como para los participantes, debido que al primero le sirve para guiarse respecto a la temática a investigar y a analizar, y al segundo, para dar su opinión libremente, de acuerdo a la estructura flexible del instrumento, que pretende obtener las perspectivas y puntos de vista de los participantes (sus emociones, prioridades, experiencias, significados y otros aspectos subjetivos).

El procedimiento de análisis implicó la contextualización y organización significativa de las entrevistas, según frases significativas; identificación de temas y subtemas (elaboración de índice temático); escritura y redacción del análisis por tema.

ANÁLISIS DE DATOS

\begin{tabular}{|l|l|}
\hline Pregunta & Categorías \\
\hline ¿Quiénes son los mapuches? & 1.- Comunidad independiente. \\
& 2.- Componente cultural. \\
& 3.- Ancestros. \\
& 4.- Indígenas. \\
\hline
\end{tabular}

\section{Categoría 1- Comunidad independiente}

Según la apreciación de los profesores en formación, los mapuches entrarían dentro de la categoría de "comunidad independiente" debido a que, estos tienen una cultura, civilización y estructura social que se diferencia de la nacional, lo que los hace visibilizarse de otra manera.

Sujeto C: Yo lo podría definir como otra cultura, porque vemos otra civilización, otros métodos, otra como estructura de su sociedad, porque éstas..., se representan de otra manera, (...), pero..., este es como el pueblo 
que ha permanecido y trascendido a través de la historia, yo lo veo como cultura, es otra civilización, dentro de nuestro país.

\section{Categoría 2 - Componente cultural}

Por otro lado, se identifica a los mapuches como un componente cultural debido a que, se perciben como una subcultura dentro de la cultura nacional o como un componente en la cultura hispano chilena en la zona central, refiriendo al contexto que habitaba antiguamente este pueblo prehispánico.

\section{Sujeto E: Una cultura dentro de nuestra cultura,}

Sujeto P: Bueno desde mi percepción, creo que es uno de los componentes de la cultura hispano chilena, comprendida en la zona central.

Hecho también visibilizado por el Estado chileno cuando en la Ley $N^{\circ}$ 19.253, reconoce la existencia de agrupaciones humanas en el territorio nacional desde el periodo prehispano, conservando sus diversas manifestaciones.

\section{Categoría 3- Ancestros}

En esta categoría se hace alusión a que el pueblo mapuche representa las raíces o ancestros de Chile vale decir, se trataría de un pueblo aborigen no dominado y que mantiene su cultura, siendo originario puesto que, antes de la llegada del español habitaba ya este territorio,

Sujeto E: Pero hace 10 años atrás cuando mataron a Matías Catrileo, ellos hacían la aclaración que ellos no eran un pueblo indígena, porque indígena es un nombre que ocupa el Huinca y que significa el domesticado, porque es una palabra que viene totalmente de afuera, ellos son aborígenes ellos nacieron ahí son de ahí, entonces esa es la diferencia ellos no son indígenas, ellos son aborígenes porque indígenas significa que están domesticados, cachay que ellos están dominados, ellos no están dominados.

Sujeto B: o sea mantienen su cultura, más bien su cultura, o sea mezclado un poco, pero igual conservan la esencia y están intactos. Para mi yo los considero como las raíces.

Tal y como hace referencia José Bengoa (2012), los mapuches y los otros pueblos originarios no eran bandas cazadoras y recolectores que fueron conquistadas simplemente por el español, como se le ha visto desde la historiografía tradicional, sino que, existía una organización social o varias organizaciones bien estructuradas, que produjeron el asentamiento mapuche antes de la llegada del español al territorio chileno, cuando el pueblo araucano invadió a una civilización preincaica, conocida como la cultura chincha chilena.

\section{Categoría 4- Indígena}

En esta categoría se visualiza al mapuche como un pueblo con su propia gente, tradiciones y cultura, que el Estado debe reconocer, respetar y darle la importancia que merece como pueblo, 
Sujeto D: (...) Entonces, como que para mí en lo personal, este pueblo siempre ha sido desplazado nunca se le ha dado una relevancia y el respeto que se merecen, porque también son personas, independiente que tengan una cultura son personas, porque a ellos nunca, no sé si será el Estado o quien será darle el reconocimiento que ellos se merece así como muchos pueblos más (...)

Para lo cual, el Estado en su diagnóstico del desarrollo cultural del pueblo mapuche, establece una aproximación al concepto de pueblo indígena, el cual distingue por sus propias condiciones culturales, sociales, económicas e históricas, lo que implica su propio catálogo de derechos que abarcan los derechos políticos, derechos consuetudinarios, derecho a tierras y territorios, y recursos naturales; y derechos en materia de empleo, educación, seguridad social y salud.

\begin{tabular}{|l|l|}
\hline Pregunta & Categorías \\
\hline ¿Con qué asocias a los mapuches? & 1.-Territorio araucano. \\
& 2.-Dominación cultural. \\
& 3.-Conflicto. \\
& 4.-Barbarie. \\
\hline
\end{tabular}

\section{Categoría 1.- Territorio Araucano}

En esta categoría se asocia al mapuche con el territorio araucano debido a que, el mapuche es muy apegado a la tierra y naturaleza, posiblemente por los lazos familiares que ahí se crean,

Sujeto R: "Yo..., al mapuche lo asocio con la tierra en general, un pueblo que está muy apegado al lugar donde vive, que... que se siente más perteneciente al lugar donde está, que posiblemente los lazos familiares, que los lazos familiares los hacen en el lugar donde ellos están, muy apegados a la tierra y a la naturaleza en sí..."

Según los historiadores contemporáneos como Jorge Pinto (2012) y José Bengoa (2012), la Araucanía en su conjunto es un espacio geográfico diferente, el cual debe ser estudiado como una macroregión, debido a sus características históricas, políticas, económicas y socioculturales diferentes al resto de Chile.

\section{Categoría 2- Dominación Cultural}

En esta categoría, se asocia al mapuche a dominación cultural, y por tanto al proceso de formación del Estado chileno, viéndolo como un actor activo, e identificándolo comúnmente con el papel de vencido por lo vencedores,

Sujeto S: ( ...) Y un poco sumado a eso, yo he escuchado algunos comentarios, en relación al término de los vencedores y los vencidos, en cuanto a lo que es el pueblo mapuche y a lo que es la formación del Estado Chileno (...)

Estos vencedores según lo plantean los participantes, serían los patriarcas de la nación, parte de una sociedad y cultura blanca que se instaló en la región, tomando para si las tierras mapuches, y enviando a este pueblo mayoría numérica pero minoría práctica a reservaciones, donde desarrollaban su propia cultura pero, lejos de las ciudades. Desde 
su perspectiva, ello explicaría el surgimiento de una cultura de resistencia que finalmente les permite sobrevivir y permanecer.

\section{Categoría 3 - Conflicto}

En esta categoría se asocia a los mapuches, con la expresión conflicto y resistencia al orden establecido.

Sujeto D: “Con el conflicto, con algunos territorios, con la aculturación, etc."

Esto debido a que, históricamente se reconoce la existencia de un conflicto el cual, encuentra sus causas en la década de 1860 en donde, en primera instancia personas particulares, especuladores y militares como también el Banco y el Estado, al reconocer al mapuche como un ciudadano chileno en pleno derecho, en su afán de integración tanto política como territorial, permite la transacción y facilita la usurpación de estas tierras en la frontera, sin tener los mapuches un criterio de valor en cuanto a ellas. Lo que provocaría a través de los años que, civiles como colonos y sus descendientes a través del tiempo se vieran involucrados en situaciones de violencia, despojos e incendios, por una falta de reglamentación del Estado en esta materia y toma de decisiones que afectaban directamente a las comunidades en su cosmovisión e impacto ambiental negativo a sus comunidades, tal como lo señala el marco referencial,

\section{Categoría 4 - Barbarie}

Según las apreciaciones de los estudiantes que fueron parte de esta investigación, al mapuche también se le asocia con expresiones del tipo bárbaro y salvaje, en una historia comúnmente escrita desde una mirada vencedora por la sociedad chilena, tal como se señala a continuación,

Sujeto S: “(...) por ejemplo; muchas veces se habla del mapuche como este ser bárbaro, salvaje, de escasa organización política, e increíblemente eso los llevó a resistir tantos años y sumado a esa idea vencedor, vencido, muchas veces se enseña una historia muy distinta a la historia mapuche y ellos mismos tienen esa concepción, que nuestra historia es mal contada, que la cuentan los vencedores, en algunos casos, la cuenta la sociedad chilena, que algunas veces realmente muchos no saben (...)"

Como también lo detallan historiadores de la talla de Francisco Encina, para el cual si bien este pueblo originario no era considerado como primitivo si lo era como salvajes en Estado de barbarie, debido a sus prácticas culturales y características guerreras como la resistencia y trato con los vencidos en las batallas, los hacían ver como seres de feroces sentimientos que causaban horror a los ojos del conquistador europeo observador.

Para perpetuar en su raza estos feroces sentimientos, aquellos salvajes hacían que sus hijos aprendiesen desde niños a descuartizar los miembros de sus víctimas, a arrancarles las carnes y a atormentarlas en su agonía. (Barros 2000: 117)

Estos hechos que se observaron y narraron por los españoles causan en el que escribe un completo sentimiento de horror y de barbarie existente, llegando a decir que su pluma, elemento con el cual escriben en ese tiempo, se resiste a describir en todos sus aspectos este tipo de cuadros. 
"El "bárbaro y sanguinario salvaje" que vivía del maloqueo y las tropelías, el "peligroso indio" que impedía la colonización y ocupación productiva de las tierras del sur, (...)" (Bengoa: 2012: 333)

\begin{tabular}{|l|l|}
\hline Pregunta & Categorías \\
\hline $\begin{array}{l}\text { ¿Cuál es la importancia del pueblo mapuche } \\
\text { dentro de la Historia de Chile? }\end{array}$ & $\begin{array}{l}\text { 1.- Valoración económica del estado. } \\
\text { 2.- Resistencia mapuche. }\end{array}$ \\
& 3.- Legado araucano. \\
& 4.- Menosprecio cultural. \\
\hline
\end{tabular}

\section{Categoría 1 Valoración Económica del Estado.}

Una primera importancia reconocida al pueblo mapuche se relaciona con la valoración económica del Estado respecto al aprovechamiento de sus tierras, esto se puede ver expresado en,

Sujeto S: Y utilizados también los mapuches, por el estado... básicamente es radical su importancia, como decía el compañero, no sé, leyendo un poco, desde 1900 a la fecha, la mayoría de los fundos son de privados, y son las hectáreas casi más grandes de Chile, entonces claro algo mercantil, capitalista por parte del estado, obviamente sirven las tierras ancestrales del pueblo mapuche al estado, es algo netamente económico creo yo.

Expresando que las tierras ancestrales de los mapuches, han sido utilizadas como una fuente económica por parte del Estado, las cuales comenzaron a ser ocupadas desde los gobiernos liberales en 1861

\section{Categoría 2- Resistencia mapuche}

Se asocia la importancia del pueblo mapuche a la resistencia ofrecida a lo largo de los siglos, causada por la conquista de la cultura occidental sobre la cultura y forma de vida autóctona del pueblo mapuche,

Sujeto L: "Yo creo que la importancia histórica que tiene el pueblo mapuche, relacionado a la resistencia de este pueblo, ante el avance de la cultura occidental, (...), entonces, para nosotros la historia de los mapuches, es la historia de la guerra entre la cultura de nosotros y la de ellos..."

En esta guerra de culturas el pueblo mapuche ha resistido, defendiendo constante y arduamente sus tierras, aun sabiendo que bien podía morir en esta defensa puesto que, al observar sus armas y las del español, la lucha era muy desigual. Siempre movilizado por la necesidad cultural y vital de defender su propia idiosincrasia,

\section{Categoría 3- Legado araucano.}

También se releva el legado cultural que el pueblo mapuche representa en nuestra sociedad y que cada uno posee en sí mismo, observándose esto en el lenguaje, expresiones culturales como bailes folclóricos, alimentos, formas de cocinar, etc. Tal y como hace referencia un estudiante del nivel 500 cuando dice que, 
Sujeto E: "Yo creo..., yo creo que es la base de la cultura eh..., del centro, del centro sur, son la base de la cultura, porque nosotros todavía tenemos esa..., esa mezcla y todavía mantenemos cosas y vacíos, como el idioma, como en..., por ejemplo; el folclore que tenemos, que también, esa mezcla, que también tiene rasgos de la cultura mapuche, y eso..., yo creo que esa, es la importancia, los vestigios que tienen en nosotros mismos"

Dentro de estos vestigios o legado cultural valorado como algo nacional, el Estado cada vez que enfrenta el desafío identitario ha tomado el problema indígena, desde una perspectiva heroica, de guerra a muerte o sangre derramada en defensa de la libertad, donde, después de la consolidación de la Republica héroes de antaño y, por otra parte el simbolismo de sangre derramada es utilizada en el color rojo de la bandera chilena, como una forma de representatividad nacional.

\section{Categoría 4- Menosprecio cultural.}

Emerge también en el discurso de los profesores en formación, la conciencia de un claro menosprecio cultural, como cuando se afirma que,

Sujeto E: "Yo creo, que no se le ha dado mucha importancia al pueblo mapuche, sino que más ... bien lo vemos, en general como un museo, porque nosotros vamos a ver, vamos al lugar y vemos oh que el mapuche es aquí, que bonito, como ocupan sus cositas, la ropa, la comida típica y más allá que hacemos, no hay una trascendencia de sus tradiciones, nosotros no vivimos a diario con las cosas que ellos... hacen, sus tradiciones, sus costumbres, su comida, su vestir, sus cosas, yo encuentro que en la Historia de Chile ha sido menospreciada la cultura mapuche"

\begin{tabular}{|l|l|}
\hline Pregunta & Categorías \\
\hline ¿Cuál es la importancia del pueblo & 1.- Escasa relevancia. \\
mapuche en la actualidad? & 2.- Resentimiento araucano frente al Estado. \\
& 3.- Zona de terrorismo. \\
& 4.- Utilización estatal. \\
& 5.- Independencia Mapuche. \\
\hline
\end{tabular}

\section{Categoría 1- Escasa relevancia.}

Emerge en el relato una primera categoría que señala una "escasa relevancia" puesto que, la mayoría o común de las personas están influenciadas por lo que aprendieron en la escuela, en sus libros de clases de Historia y Geografía, escritos en base a la historiografía tradicional en forma de prejuicios, mitos, suposiciones, interpretaciones, falsificaciones históricas frente al pueblo mapuche y, con una cosmovisión occidental de los vencedores muy influyente en la cultura llamada hispano criolla, no interesándose en el conocimiento que otras fuentes con visiones distintas pueden ofrecer, tal como señala un estudiante en formación 
Sujeto K: "Bueno, yo creo que... tampoco no se le da la importancia, la gente habla de los mapuches, que son borrachos, son indios, que son aquí..., porque nadie tampoco intenta informarse o entender por qué ellos son así (...)"

Incluso esto es coincidente con lo planteado por la historiografía cuando refiere a los indígenas en expresiones tipo borracho, indio, incivilizado, flojo, y salvaje.

Categoría 2- Resentimiento Araucano frente al Estado.

También emerge la categoría referida al "resentimiento araucano frente al Estado", directamente relacionado con el conflicto presente y la conciencia de deuda histórica existente hacia los pueblos originarios, y sobre todo hacia el pueblo mapuche, a lo cual un estudiante del nivel 500 se refiere de la siguiente forma,

Sujeto E: (...) y como se ha visto también, en varias noticias que han dado, los estafaron antiguamente con las tierras que tenían y eso, es lo que ellos reclaman, y..., yo creo que ..., igual se da la oportunidad para conocer de ellos, cuando dan reportajes..., cuando salen hablando de las comunidades, comuneros y expresando... su resentimiento contra el Estado Chileno (...)

Categoría 3- Zona de terrorismo

Cuando se realiza la pregunta sobre la importancia del pueblo mapuche en la actualidad, emergen también relatos identificados con la expresión "zona de terrorismo",

Sujeto R: Actualmente para el Estado de Chile, se ve como una zona de problemas en realidad, visto como una zona de conflictos y todo eso seria.

Sujeto B: Y ahora, si nos colocamos a ver desde las distintas aristas que tiene, digamos, es un problema, lo asocian incluso con terrorismo, no sé y muchas veces por lo que yo he visto los terroristas no son ellos.

Es por esto, que la zona sur del país se considera como un lugar de constate conflicto, debido a los múltiples atentados que han ocurridos en específico en región de la Araucanía, poniendo en jaque el orden ciudadano.

Categoría 4- Utilización comercial estatal

En otra dirección emerge la categoría referida al uso por parte del Estado sobre el pueblo mapuche, lo cual se puede demostrar en sus dichos...

Sujeto A: Se ve como un problema pero también se le ve como algo comercial por ejemplo; el turismo porque exalta mucho la cultura mapuche, para que venga el extranjero también a visitar, siempre se le ve como algo comercial como algo para ganar.

Sujeto E: (...)la falta de respeto más grande que ha tenido Chile en este último tiempo, es colocar la figura del mapuche en la moneda a $\$ 100$ pesos, esa es la figura más ofensiva, que para el mapuche puede hacer el Estado, porque está vulnerando todo, o sea toma símbolo toma algunos elementos, pero mirando todo lo malo, o sea la importancia que tiene para Chile hoy en día es la imagen, lo que más vende ese martirismo de ser indígena, ser mapuche, vende mucho (...) 
Esta imagen también ha tendido a quedar en el vago recuerdo de guerreros antiguos, con un pasado glorioso, utilizados muchas veces como elementos de consumo o vinculados a expresiones de carácter folklóricas (Bengoa 2012)

\section{Categoría 5- Independencia Mapuche.}

Sujeto C: Su nación, su Estado.

Expresando con esta afirmación, que la importancia del pueblo araucano radica en la imagen de independencia que proyectan, debido a que se ve como un Estado aparte de Chile, lo que llevaría consigo la existencia de un territorio distinto al chileno, tanto en leyes, como en costumbres, tradiciones, en definitiva identidad.

\begin{tabular}{|l|l|}
\hline Pregunta & Categorías \\
\hline ¿Cómo te informas respecto al tema? & 1.- Medios de comunicación masiva. \\
& 2.- Literatura. \\
& 3.- Contexto Universitario. \\
& 4.- Redes sociales. \\
& 5.- Requerimientos curriculares. \\
\hline
\end{tabular}

Categoría 1- Medios de comunicación masivo.

Uno de los medios por el cual se informan los profesores en formación son los medios de comunicación masiva: diarios, televisión, radios, entre otros.

Sujeto E: Los medios de comunicación, es el constructo más común

Mientras que su compañero expresaría que, este se informó a través de la radio,

Sujeto B: La radio Villa Francia, que también está comunicando cosas, que no es de una postura de la alta sociedad o radios que tengan una función más informativas y no del interés del Estado o cosas así, un poco más objetivo no tachan por ejemplo, de terroristas al mapuche, tienen más acceso a los comuneros mapuche en este caso, que tienen más relación con ellos y tienen una relación más empática, no está el medio presente.

\section{Categoría 2- Literatura.}

Otra fuente destacada es la lectura de distintos autores, el cual se expresó de la siguiente manera,

Sujeto T: Yo creo que acercándome más a una lectura un poco más revisionista, un Julio Pinto, o algo que nos acerque más a algo como no tan escrito por fechas y esas cosas, quizás entender un poco más los contextos, pero el problema de eso es que me tengo que acercar a otros autores de otros países que estén más interesados en plantear esto, en Chile lamentablemente se está haciendo, hay muy poca información... (....)

Lo que demostraría un interés del futuro profesor en leer sobre esta temática, a partir de diversos autores tanto nacionales como internacionales, puesto que es necesario acceder a distintas versiones de los hechos históricos, si lo que se pretende en logar una adecuada compresión de los mismos. 


\section{Categoría 3 - En el contexto universitario.}

Llama la atención que el contexto universitario es reconocido como un espacio del cual es posible conocer y problematizar sobre el tema mapuche

Sujeto L: Yo como me informo acerca de esto, yo la verdad en la universidad he aprendido prácticamente todo lo que se acerca de esto, todo lo que sé acerca de los mapuches, yo llegué aquí sabiendo cuestiones muy vagas y caracterizadas por la ignorancia y el prejuicio... (...)

Desde ese punto de vista, resulta interesante conocer la mirada o perspectiva con la cual la escuela básica, el liceo y la universidad aborda la problemática en cuestión, con la intención que el alumno vaya formando su propia opinión y criterios sobre los pueblos originarios; dejando claro, que el profesor de Historia, Geografía y Ciencias Sociales cumple un rol importante a la hora de abordar contenidos asociados a esta temática.

\section{Categoría 4 - Redes sociales.}

En la actualidad, las redes sociales (internet, Facebook, twitter, entre otras) son lo más utilizado por los jóvenes, para acceder a informarse con respecto algún tema. Es por esto que una parte de los estudiantes en formación de la carrera respondieron que,

Sujeto R: Yo, ósea cuando yo fui dirigente scout en la unidad de la avanzada, teníamos como fondo motivador al pueblo mapuche, pude aprender un poco de mapudungun $y$ aprender un poco más de las celebraciones, pero básicamente era buscar en internet $y$ un diccionario en que buscábamos, y ... , más que nada eso (...)

Lo que podría preocupar es la capacidad de estos estudiantes para seleccionar adecuadamente las mejores fuentes de información.

\section{Categoría 5 - Requerimientos curriculares asociados a práctica}

Los profesores en formación señalan que un medio que la ha aproximado a la temática, son las exigencias planteadas por el marco curricular en relación al pueblo mapuche, cuando enfrentan el desafío de su práctica profesional

Sujeto F: (...) es cuando uno va a preparar las clases, me informo (...)

Sujeto N: cuando tuve que trabajar el tema indígena en mi práctica profesional de segundo medio. Aprendí cuestiones que me hicieron reflexionar y encontrar nuevos sentidos

Lo que demostraría que uno de los intereses para informarse con respecto al tema de los pueblos originarios, es por la confección de su material de apoyo para la presentación de sus clases dada la necesidad de evidenciar manejo conceptual de los temas.

\begin{tabular}{|l|l|}
\hline Pregunta & Categorías \\
\hline ¿Realiza lecturas en relación al tema? ¿Cuáles? & $\begin{array}{l}\text { 1.- Cronistas. } \\
\text { 2.- Autores Chilenos. }\end{array}$ \\
\hline
\end{tabular}

\section{Categoría 1 - Cronistas}


Como primera fuente de acceso a la temática indígena emerge el estudio de los cronistas,

Sujeto E: Los cronista po..., el cronista que leí yo fue Diego de Rosales, y él, le daba como una visión que..., era religiosa en cierta forma po... porque era un jesuita.

Lo cual demostró que ellos si han realizado estudios con respecto a los pueblos originarios chilenos, ya que los cronistas son los primeros autores que describen las características y los hechos históricos de la época de conquista y colonia. Esto dejaría como evidencia que los estudiantes han hecho lectura sobre las primeras descripciones de los araucanos como Diego de Rosales y Francisco Núñez de Pineda. Otro cronista nombrado fue Pedro de León,

Sujeto R: "Pedro de León. Otro libro también que lo vimos en introducción a la historia mapuche Francisco Núñez de Pineda que es como... Lo más relevante"

\section{Categoría 2 - Autores Chilenos.}

Otra categoría de respuesta, identifica como fuente de acceso al estudio de la temática indígena, a algunos autores nacionales como Pinto Rodríguez, el cual es uno de los historiadores del siglo XXI que ha estudiado y escrito sobre el pueblo mapuche, tanto en su relación con el Estado como de los cambios que han sufrido dentro de la historia del país.

Sujeto D: Pinto..., Pinto Rodríguez, yo creo..., que si nos pusiéramos en el sentido de ser unos ciudadanos, integrales y todo el cuento, los autores que toda persona consiente, culta, propia de un país realmente desarrollado debería leerlos.

Con esto se observa que los estudiantes tienen conocimiento con respecto a qué autores nacionales tratan esta temática, y cuál es la importancia de leer sobre estos historiadores, ya que, serían conscientes del rol de los historiadores en el desarrollo de esta disciplina y finalmente en las imágenes y representaciones que se comunican.

\begin{tabular}{|l|l|}
\hline Pregunta & Categorías \\
\hline $\begin{array}{l}\text { ¿Qué conoce acerca de la situación actual del } \\
\text { pueblo mapuche? }\end{array}$ & 1.- Conflicto histórico mapuche. \\
2.- Políticas Públicas. \\
\hline
\end{tabular}

\section{Categoría 1- "Conflicto histórico mapuche"}

El relato que emerge en todos los participantes es el referido al "conflicto mapuche", evidenciando conocimiento de la problemática actual, que experimentan las comunidades mapuches.

\section{Sujeto, Todos: EI conflicto...,}

Otro grupo de estudiantes, también hacen alusión al conflicto que existe entre los mapuches y el Estado Chileno, no obstante ellos señalaron el "por qué de este conflicto", explicando las demandas de este pueblo las cuales tienen como foco,

Sujeto B: La devolución de sus tierras, protección de recursos naturales. 


\section{Sujeto D: Sus tierras son lo que más ellos defienden.}

Los estudiantes al momento de nombrar las razones por la cual existe un conflicto, demuestran tener conocimiento actual sobre lo que está ocurriendo en Chile con los mapuches, problema que nació desde el período de la conquista y que sigue hasta el día de hoy.

\section{Categoría 2 - Políticas Públicas.}

Otro grupo de respuesta, ponen de manifiesto el tema de las políticas públicas, hacen referencia a la responsabilidad por parte del Estado de promulgar políticas públicas que promuevan la inter y multiculturalidad dentro del país en el aspecto político, educativo y cultural, tal y como lo señala un estudiante del nivel 700, el cual da su opinión sobre una nueva política que, se está analizando para beneficio del pueblo mapuche,

Sujeto E: Que actualmente se presentó en el año 2010 por parte de los loncos la implementación del método que tiene Nueva Zelanda con los Maorí que en verdad es entre comillas parecido al que estuvo en Estados Unidos con los indios Apache los Navajo que, es darle la libertad de territorio po y darle la libertad de un Estado independiente, entre comillas independiente seria casi algo como algo, casi federalista en realidad.

Este ejemplo de Nueva Zelanda, crea una esperanza para el pueblo mapuche y hace que la sociedad chilena vuelva su mirada hacia otras prácticas y programas públicos internacionales que sí han logrado dejar a atrás el conflicto étnico y caminar juntos en pos de un mismo fin de inclusión, concluyendo lo que se comenzó en el mandato del Presidente Patricio Aylwin Azocar con el Acuerdo de Nueva Imperial entre el Estado chileno y los principales dirigentes mapuches.

\begin{tabular}{|l|l|}
\hline Pregunta & Categorías \\
\hline $\begin{array}{l}\text { ¿Cuáles son las posibles soluciones al } \\
\text { conflicto mapuche? }\end{array}$ & $\begin{array}{l}\text { 1.- Cambio de concepción a nivel país, } \\
\text { respecto al indígena. } \\
\text { 2.- Nuevo rol del estado, frente al conflicto } \\
\text { al pueblo mapuche. }\end{array}$ \\
\hline
\end{tabular}

\section{Categoría 1- Cambio de concepción a nivel país, respecto al indígena.}

Consultados respecto a las vías de solución del conflicto, una primera categoría de respuesta indica la necesidad que la sociedad comience a tener una nueva mirada con respecto a los pueblos mapuches, es decir que, las personas se informen con respecto a esta temática y, a la vez lo valoren más, observándose esto en el siguiente argumento,

Sujeto D: (...) si se quiere hacer un cambio ahora tiene que ser todo Chile que tiene que entender ¿Quién es esta gente? ¿Cómo son? ¿Qué hacen? Y después entraríamos nosotros los profesores, y después los estudiantes y para hacer todo ese ciclo capaz que ni estemos.

Demostrando así que, los profesores tienen la responsabilidad de enseñar y cambiar la concepción de la sociedad a nivel nacional. Dejando como responsabilidad del cambio a los docentes.

Categoría 2 - Nuevo rol del Estado, frente al conflicto del pueblo mapuche. 
Complementando lo anterior, está la categoría según la cual se precisa un nuevo rol del estado frente al conflicto, como se expresa en

\section{Sujeto E: (...) que el estado cambie su rol, para la comunidad mapuche (...)}

Lo cual, no estaría alejado de otras respuestas que señalan la necesidad de un cambio que debe ser liderado por el Estado, y consistiría en,

Sujeto A: (...) una entrega del territorio, un reconocimiento por parte del Estado y por parte de la nación en general y una también por la deuda histórica que se tiene con el pueblo originario más que nada.

Sujeto O: El estado no quiere ceder, no le conviene por el tema forestal, por el tema si le regalo una tierra a un mapuche, la va a disfrutar, no la va a trabajar, por ende no le dará ingreso económico.

Es por esto que, se hace necesario que el Estado cambie su rol y pensamiento frente al pueblo mapuche, no viéndolo más desde su propia visión capitalista sino, que desde la cosmovisión del pueblo originario investigado.

\begin{tabular}{|l|l|}
\hline Pregunta & Categorías \\
\hline $\begin{array}{l}\text { ¿Qué políticas públicas conoce respecto al } \\
\text { pueblo mapuche? }\end{array}$ & $\begin{array}{l}\text { 1.- Becas indígenas. } \\
\text { 2.- Leyes civiles. }\end{array}$ \\
\hline
\end{tabular}

\section{Categoría 1- Becas indígenas.}

Al momento de preguntar sobre las políticas públicas que están destinadas a los pueblos mapuches, se identifican en primer lugar las becas indígenas, las cuales como lo señala un estudiante les beneficiaria en aspectos económicos y de educación,

\section{Sujeto E: Como ingreso económicos...como el tema de estudiar (...)}

Lo cual se viene tratando desde fines del siglo XX, con políticas de gobierno por parte de la concertación la cual, en sus periodos gubernamentales creó e implementó diversas políticas, tales como las becas de estudio, el fomento al desarrollo rural, la salud intercultural, entre otros, que buscan responder a las necesidades agrícolas, educativas, culturales y también políticas de este grupo de ciudadanos.

\section{Categoría 2- Leyes civiles.}

En esta categoría se señaló que, una de las políticas públicas con respecto al pueblo mapuche es la utilización del lenguaje mapudungun en el registro civil y en diversos actos solemnes como por ejemplo en la unión civil o, simplemente en los letreros que señalan el servicio que cada departamento presta al usuario, paso que consideran mínimo pero a la vez esperanzador en la inclusión del componente cultural mapuche en las instituciones estatales. 
Sujeto E: En el registro civil que hay algunas cosas que están en mapudungun

\begin{tabular}{|l|l|}
\hline Pregunta & Categorías \\
\hline ¿Cómo está incorporado el contenido del pueblo & 1.- No se tiene conocimiento. \\
mapuche en el marco curricular? & 2.- Nivel de enseñanza media. \\
& 3.- Nivel de enseñanza básica. \\
\hline
\end{tabular}

\section{Categoría 1- No se tiene conocimiento.}

Una parte de los profesores en formación entrevistados responde no tener conocimiento respecto al tema

Sujeto E: Uno de los compañeros sabia, en segundo medio. A nosotros se nos pasó esto, pero ninguno nos acordábamos.

De lo cual se desprende que, no todos los estudiantes de la carrera, poseen el conocimiento y dominio completo, o no recuerda los contenidos mínimos obligatorios definidos en los programas de estudio, tanto de nivel de enseñanza básica, como media, de la asignatura con la cual se trabaja, en este caso, Historia, Geografía y Ciencias Sociales.

Categoría 2- Nivel de enseñanza media.

Otro grupo de profesores en formación, respondieron lo siguiente

Sujeto D: Segundo medio, pero es como la ubicación, lo político, lo religioso...con el típico mapa, colocarlo y mágicamente hasta ahí llegamos, no estoy seguro si se pasa el tema de la pacificación de la Araucanía...

\section{Sujeto F: Dentro de la Incorporación Territorial y la Conformación del} Estado Nación, de mapa de segundo medio...

Se analiza que el docente en formación posee cierto manejo y noción de los contenidos mínimos obligatorios, expuestos en los programas de estudio de Historia, Geografía, y C.S, esto se refleja en que los estudiantes de pedagogía en formación, aseguran que el contenido del pueblo mapuche, se estudia y trabaja en el nivel de enseñanza media, en específico en segundo medio, lo cual está correcto, ya que al recurrir a la revisión del programa de estudio, dichos tópicos se ubican en la Unidad 1 de este curso, denominada; Legado Colonial, y Unidad 3, llamada; La conformación del territorio chileno y de sus dinámicas geográficas, detallándose de la siguiente manera, en cuanto a sus contenidos específicos:

\section{Unidad, Contenidos:}

> Pueblos originarios chilenos: características propias antes y después de la conquista española, su legado cultural, sincretismo entre los pueblos indígenas y la cultura española. > Proceso de formación de la sociedad colonial: economía y sociedad, condición jurídica y disminución de la población indígena, mestizaje, instituciones. , Guerra de Arauco: fases del conflicto, frontera, rebeliones, esclavitud y parlamentos. > Chile colonial: el imperio español y la posición de Chile en él; organización política y administrativa; actividad económica; estructuración 
de la sociedad. > Proceso de desarrollo de la sociedad colonial en Chile: comercio, vida urbana, reformismo borbónico y centralismo. , Confrontación de interpretaciones historiográficas y presencia indígena en Chile contemporáneo

\section{Unidad, Contenidos:}

> Proceso de conformación y ocupación del territorio. > Proceso de formación del territorio por diversas vías, incluida la bélica. > Proceso de desarrollo económico y social del territorio con aportes regionales específicos. > Proceso de incorporación de nuevos territorios durante el siglo XI

Sin embargo, a pesar de que participantes conocen el curso donde se enseñan estas temáticas, como también algunos de los contenidos que se trabajan, los manejan de forma dispersa y general, reflejando un dominio que aún es parcial de la organización de las unidades.

\section{Categoría 3- Nivel de enseñanza básica.}

Otros identifican en el nivel de la enseñanza básica sin embargo, con disparidad en los cursos que en específico deben abordar la temática. Por otro lado, no logran precisar con claridad ni los contenidos asociados, ni los objetivos de aprendizaje comprometidos.

Sujeto E: Sexto básico...

Sujeto R: Tercero o cuarto básico, una pincelada no más Historia de Chile

\begin{tabular}{|c|c|}
\hline Pregunta & Categorías \\
\hline $\begin{array}{l}\text { ¿Cuál es el rol del profesor de Historia, } \\
\text { Geografía y Ciencias Sociales en el aula, } \\
\text { en cuanto a la valoración de los pueblos } \\
\text { originarios? }\end{array}$ & $\begin{array}{l}\text { 1.- Enseñanza y aprendizaje significativo. } \\
\text { 2.- Docente reflexivo. } \\
\text { 3.- Concientización de profesor, frente a la } \\
\text { temática mapuche. } \\
\text { 4.- intereses transversales de los estudiantes. }\end{array}$ \\
\hline
\end{tabular}

\section{Categoría 1 - Enseñanza y aprendizaje Significativo}

La Guerra de Arauco es una de las más recordadas dentro de las relaciones entre el Estado y el pueblo mapuche, por historiadores, personajes emblemáticos, profesores y estudiantes, debido a la preponderancia que se le otorga por sobre otros contenidos, ya sea por la cantidad de muertes, constantes batallas, años de duración y existencia de diversas campañas de conquista por parte del español que tuvo lugar en nuestro territorio nacional que, la hicieron incomparable a ninguna otra guerra, tal como lo indica Encina siendo una

"Guerra sin ejemplo y sin rival en cuanto a heroísmo - dice Errázuriz- si se la considera en conjunto y no se mide por el número de los combatientes, sino por la pujanza y la gloria de los hechos de armas" (Encina 1949: 264)

Sin embargo, esta relevancia que se le da en cuanto a los personajes que participaron, nombres de batallas, fechas específicas no tienen trascendencia sino, se analiza el contexto y se interpreta lo sucedido en base a diversas fuentes históricas, utilizando el contenido como medio y herramienta para conocer y tomar decisiones en la realidad actual, donde se requiere para ello una enseñanza y aprendizaje significativo que, se 
vincule a la vida cotidiana y practica del estudiante, tal como lo señala un estudiante en formación,

Sujeto E: Dar una información que sea significativa, no simple memoria para contestar una prueba de alternativa o no... Creo que eso no serviría de nada, a mí no me serviría de nada, yo cuando estuve en el colegio y me hicieron aprenderme cosas de memoria, alternativas, (...) en el nivel de grado taxonómico, no me servía de nada porque se me olvidaba (...) algo que sea más servicial, que les pueda ayudar a entender mejor lo que es la cultura mapuche.

\section{Categoría 2 - Docente Reflexivo}

Según los estudiantes en formación, el rol del docente debe ser el de una persona crítica que haga reflexionar a sus estudiantes sobre diversas temáticas más allá de la mera transmisión de contenidos que, lo que hace generalmente es imponerle una visión predeterminada a los estudiantes sobre los sucesos, acontecimientos y procesos históricos, lo que provoca también que, el estudiante no cree su propia opinión y por lo tanto, no genere su propia motivación por investigar y/o aprender, a lo que en relación a esto, un estudiante del nivel 700 señala lo siguiente,

Sujeto D: (...) pero nosotros deberíamos pasar todo (contenidos) pero con unos matices intermedios, yo no puedo decirle joven, ;usted tiene que leer esto!, porque yo le digo, yo tengo que crear en el alumno que él tenga su propia opinión no sé qué con que directrices o patrones yo no sé cómo será, pero yo creo que para allá debe apuntar esto. Nosotros deberíamos ser un profesor reflexivo cuesta con el tiempo también, pero para allá vamos.

\section{Categoría 3- Concientización del profesor, frente a la temática mapuche}

El docente actual debe crear en sus estudiantes según esta categoría, una conciencia y sensibilidad respecto a la temática mapuche, la cual, se cree en base a una presentación de diversas fuentes historiográficas que aludan a diferentes perspectivas $\mathrm{u}$ opiniones respecto a los hechos, cambiando para ello la dinámica escolar en donde, se estudia al pueblo mapuche como algo antiguo, visto desde la perspectiva de lo otro, a lo que hay que solamente identificar y conocer de forma superficial, a lo que una estudiante del nivel 700 dice lo siguiente,

Sujeto A: A mí cuando me hicieron pasar eso el profe me dijo: usted tiene que hablar la parte económica, cultural y lo que es de juegos pero era como que no te daba espacio para que hablaras sobre el pensamiento indígena.

El docente requiere comprender el pensamiento del pueblo originario mapuche y sus estructuras y, para concientizar a los estudiantes de las reales causas y procesos que está viviendo la nación, desde diferentes perspectivas que crearan en el docente y estudiantes una visión más objetiva de los hechos, que es lo que busca constantemente la historia, para una toma de decisiones consciente de la realidad.

\section{Categoría 4 - Movilizar intereses más transversales en los estudiantes}

Según las opiniones de algunos profesores en formación, el profesor debe ser un constante estímulo para que sus alumnos se motiven y deseen aprender e investigar las 
temáticas presentadas, esenciales para un efectivo desarrollo ciudadano y aporte real a la sociedad, como lo señalan dos estudiantes del nivel 900,

\begin{abstract}
Sujeto F: Según mis prácticas, mi rol lo veo como estar pendiente, de aquel alumno, provocar su interés en lo que está aprendiendo, que descubra el sentido e interés en estas temáticas que tienen que ver con nosotros, y hay que estar preparada para responder esas inquietudes, hasta el momento, ese vendría siendo mi rol.
\end{abstract}

Sujeto E: No en los puros conocimientos, te centras en pasar los contenidos, pero tienes que darte tiempo para motivar, ayudar a encontrar y descubrir sentido...

\title{
CONCLUSIONES
}

Los docentes en formación, si bien presentan conocimientos generales respecto al desarrollo histórico que ha tenido el pueblo mapuche en nuestro territorio y, la influencia de su legado en la cultura chilena, reconocen que la problemática mapuche no ha logrado ser relevada suficientemente dentro de su formación y bagaje, aun cuando se dan cuenta que es una temática necesaria de trabajar en el transcurso de la educación media. No han logrado desde el punto de vista curricular, precisar cuáles son los objetivos de aprendizaje y contenidos educativos involucrados, ni tampoco logran ser plenamente consciente del rol que, como profesores de historia, geografía y ciencias sociales les corresponden, con representaciones que aun son muy generales.

Por otra parte, se puede mencionar que, el rol social del docente es importante debido a que, si este no tiene los conocimientos, habilidades y conciencia socio - cultural necesarias para ejercer su labor, evidenciando probablemente dificultades para lograr que sus estudiantes se transformen en personas informadas, reflexivas y críticas en relación, con una tema tan contingente como es la situación actual del pueblo mapuche.

En relación a la valoración que tienen los docentes en formación sobre el pueblo mapuche, las representaciones refieren a una comunidad independiente, argumentando que se trataría de una cultura completamente distinta a lo que es el Estado Chileno, siendo un componente cultural clave en la conformación de la nación, constituyen los ancestros, grupo de antepasados indígenas del cual descendemos racialmente la gran mayoría de chilenos, reconociendo la existencia de un conflicto nacional por la disputa del territorio araucano, el cual partió en la época de la conquista con métodos de dominación cultural por parte del conquistador europeo, justificando éste su actuar en la barbarie y salvajismo de los nativos de este Nuevo Mundo descubierto por ellos.

Según este discurso manifestado por los participantes, se puede observar que su noción y percepción acerca de quiénes o qué es ser mapuche está basada principalmente en la enseñanza preferentemente formal en establecimientos de educación básica, media y universitaria, con utilización de términos sesgados anclados en el tradicionalismo y, no términos como originarios o nativos los que sí aluden a una corriente historiografía más crítica que en el pasado $\mathrm{y}$, que es utilizada contemporáneamente por los historiadores. Además se puede recalcar, que si bien los estudiantes muestran variedad de términos para referirse al pueblo mapuche, no hacen una distinción entre los alcances de dichos conceptos, como sí lo hace esta nueva forma de hacer historia con referentes en Jorge Pinto y José Bengoa. Pareciera ser que este grupo de profesores en formación no han 
logrado desprenderse de las visiones historiográficas radiocanales y recién en el contexto de la formación inicial universitaria inician la apertura a nuevas formas de estudiar y comprender la historia, con las implicancias disciplinarias, pedagógicas y transversales que ello implica.

Respecto a la valoración del pueblo mapuche, se puede concluir que las representaciones de estos profesores en formación, refieren a una temprana y casi exclusiva valoración económica por parte del Estado del espacio ocupado por el pueblo mapuche, menospreciando cultural y socialmente la cultura mapuche hasta hoy en día, con imágenes que asocian a la comunidad mapuche básicamente al conflicto permanente que tienen con los chilenos, debido a los pugnas y disputas territoriales históricos.

Relacionado con el contexto anterior, podemos observar que los participantes del Focus Group no valoran significativamente para sí mismos al pueblo y cultura mapuche, lo que se evidencia en la forma y escasa indagación que realizan sobre la temática tratada, puesto que reconocen que si no es por los medios de comunicación y las lecturas asignadas en la universidad o establecimiento en el cual se encuentren realizando su práctica pedagógica (independiente el nivel en el que este el estudiante) la problemática mapuche no figura dentro de sus focos de interés ni como estudiantes, ni como profesores en formación. Si reconocen, la necesidad de fortalecer el dominio de esta área para el desarrollo de la docencia.

Consultados respecto a la importancia que los profesores de Historia, Geografía y Ciencias Sociales, le otorgan a la cultura y conflicto mapuche, es posible encontrar niveles de relevancia diversos. Esto se manifiesta en las opiniones y argumentos entregados por los participantes, los cuales creen que la influencia del pueblo se evidencia en tradiciones y formas de vida, identidad nacional y vestigios del pasado, destacando en el plano emocional, el sentimiento y espíritu de lucha con el que se autoidentifica el chileno contemporáneo.

Plano emocional también observado en el conflicto mapuche actual el cual, como reconocen los docentes en formación es un problema histórico y actual, solamente solucionable en primera instancia a través de la implementación de políticas públicas, a parte de las económicas y educativas ya existentes como becas indígenas, que traten de reparar el daño causado y la deuda histórica de Chile con el pueblo originario mapuche.

Lo que implicaría de por sí una situación de beneficios y perjuicios para cada uno de los actores involucrados, ya sean comunidades mapuches como instituciones públicas o civiles, como por ejemplo el cambio en la concepción que como país, se tiene del indígena, al cual se le relaciona con un pasado bárbaro, salvaje, flojo y borracho, el surgimiento de un nuevo rol del Estado basado en el reconocimiento y respeto de la multiculturalidad y, si fuese necesario la autonomía de las comunidades mapuche políticamente, tal y como señalaron los participantes de los Focus Group.

Frente a determinar el grado de conocimiento y apropiación del marco curricular, respecto a tema de los pueblos originarios, los docentes en formación no conocen ni manejan como profesionales de la educación, los contenidos en un orden secuencial tal y como aparecen en los programas de estudios, basándose para responder en su experiencia escolar propia, como la adquirida en práctica cuando señalan, qué contenidos y la forma de incorporación específica del pueblo originario mapuche en 
estos niveles, lo que hace concluir que el conocimiento que poseen los docentes en formación respecto al tema de investigación es vago y de interés como indagación particular. Desde la perspectiva curricular, estos profesionales en formación necesitan precisar el conocimiento del propósito formativo y la progresión que establece el curriculum nacional en relación a la temática indígena.

En cuanto a la apropiación de estos contenidos en la formación y desarrollo histórico como nación, otorgando a los ciudadanos una base de identidad mestiza, los docentes reconocen que en la apropiación del Marco Curricular respecto al tema mapuche están al debe, puesto que, si no conocen específicamente los contenidos y no han realizado un estudio minucioso de ellos, salvo algunos estudiantes que les ha tocado en su práctica pedagógica trabajar con la Unidad 1 y 3 en segundo medio, difícilmente pueden manejar y readecuar los contenidos mínimos obligatorios y aprendizajes esperados a las características y necesidades especiales y particulares de sus estudiantes.

Desde el punto de vista del dominio de la temática mapuche, los profesionales en formación presentan un débil manejo de las diversas visiones historiográficas que les permitan tener un panorama general y lo más completo posible respecto a cómo se presenta la relación Estado - Pueblo Mapuche actualmente. Con la implicancia que ello pueda tener al enfrentar el desafío de trabajar dicho contenido con sus futuros estudiantes de enseñanza media.

Recordemos que desde el punto de vista transversal, el profesor de media debe promover en sus estudiantes: conocer y valorar la historia y sus actores, las tradiciones, los símbolos, el patrimonio territorial y cultural de la nación, en el contexto de un mundo crecientemente globalizado e interdependiente; y por otra parte, reconocer y respetar la igualdad de derechos entre hombres y mujeres y apreciar la importancia de desarrollar relaciones que potencien su participación equitativa en la vida económica familiar, social y cultural.

Finalmente, nos encontramos con un grupo de estudiantes de pedagogía que se enfrenta al desafío formativo de reconocer los aportes pasados y presentes provenientes de los diversos grupos étnicos, lingüísticos, religiosos e ideológicos que han configurado y configuran la comunidad en que vive.

\section{BIBLIOGRAFÍA}

BARROS, D (2000): Historia General de Chile tomo I - Editorial Universitaria y el Centro de Investigaciones Diego Barros Arana de la Direcci6n de Bibliotecas, Archivos y Museos, segunda edición - Santiago.

BARROS, D (2000): Historia General de Chile tomo II - Editorial Universitaria y el Centro de Investigaciones Diego Barros Arana de la Direcci6n de Bibliotecas, Archivos y Museos, segunda edición - Santiago.

BENGOA, J (2012): Historia del pueblo mapuche "siglo XIX y XX" - Editorial LOM Santiago.

BURKER, P(1996): Forma de hacer Historia - Editorial Alianza - Madrid.

ENCINA, F (1949): Historia de Chile desde la prehistoria hasta 1891 - Editorial Ercilla - Santiago de Chile.

FERNÁNDEZ, F (2005): El currículum en la educación intercultural bilingüe: algunas reflexiones acerca de la diversidad cultural en la educación Cuadernos Interculturales. 
http://www.redalyc.org/articulo.oa?id=55200402

HERNÁNDEZ, R (2010): Metodología de la investigación - Editorial McGraw-Hill Interamericana- México.

MINISTERIO DE EDUCACIÓN (2011): Estándares orientadores para egresados de carrera de pedagogía en educación básica - Lom - Santiago

MINISTERIO DE EDUCACIÓN (2012): Estándares orientadores para egresados de carrera de pedagogía en educación media - Lom - Santiago.

MINISTERIO DE EDUCACIÓN (2009): Objetivos Fundamentales y Contenidos Mínimos Obligatorios de la Educación Básica y Media. Lom- Santiago

MINISTERIO DE EDUCACIÓN (2011): Programa de estudio segundo año medio.

MINISTERIO DE EDUCACIÓN (2013): 'Programa de estudio segundo año básico.

MINISTERIO DE EDUCACIÓN (2013): Programa de estudio sexto año básico.

MUNZENMAYER, A (2012): Historiografía y transposición didáctica en los textos escolares de Historia de Chile

http://revistadehistoriaygeografia.ucsh.cl/images/revistas/hyg27 art minte.pdf

PINTO, J (2012): Araucanía, siglo XIX y XX "economía, migraciones $y$ marginalidad”, Editorial Universidad de los Lagos - Osorno.

YOPO, M (2012): Políticas sociales y pueblos indígenas en Chile. Aproximación crítica desde la noción de agencia,

http://www.scielo.cl/pdf/universum/v27n2/art 11.pdf

Consejo Nacional de la Cultura y las Artes. "Diagnóstico de desarrollo cultural del pueblo mapuche".

http://www.cultura.gob.cl/estudios/observatoriodiagnosticodedesarrolloculturaldelpuebl omapuche. htm

Constitución Política de Chile. http://www.oas.org/dil/esp/Constitucion_Chile.pdf Ley general de educación. http://www.leychile.cl/Navegar?idNorma=1014974\&idVersion=

Ministerio de educación (2011): Estudio sobre la implementación de la Educación Intercultural

Bilingüe.

http://www.mineduc.cl/usuarios/intercultural/doc/201111041303130.Estudio_PEIB.pdf 